\title{
O DISPOSITIVO DA INCLUSÃO ESCOLAR E A PRODUÇÃO DE SUBJETIVIDADES
}

\author{
THE DEVICE OF SCHOOL INCLUSION AND THE PRODUCTION \\ OF SUBJECTIVES
}

\author{
Neusete Machado Rigo (neusete.rigo@uffs.edu.br) \\ Universidade Federal da Fronteira Sul - UFFS
}

\section{Resumo:}

Este artigo discute o processo de inclusão escolar e seus enredamentos com a questão das diferenças e da pedagogia. Parte do pressuposto que a inclusão é um dispositivo que afeta a pedagogia das escolas. Objetiva-se nesse estudo refletir sobre os efeitos dos processos de inclusão escolar na pedagogia das escolas, e também que subjetividades eles estão produzindo. Metodologicamente, trata-se de uma pesquisa qualitativa que desenvolve a análise documental e a descrição e análise de práticas segundo referenciais foucaultianos, utilizando especialmente os conceitos-ferramenta dispositivo, governamentalidade, subjetividade, e ainda, a noção de experiência. Como resultados, essa pesquisa aponta que o dispositivo da inclusão afeta as pedagogias das escolas desenvolvendo processos inclusivos que levam à normalização dos sujeitos, gerando subjetividades inclusivas. Mas também põe em funcionamento práticas que respeitam e acolhem os sujeitos e suas deficiências, sob uma ética da alteridade que está criando outras subjetividades. As conclusões indicam que os enunciados sobre as diferenças, que compõem o processo de inclusão escolar, estão mobilizando encontros com o outro e fabricando neste experiências, as quais transformam os sujeitos e acabam produzindo subjetividades sensíveis às diferenças.

Palavras-chave: Diferenças; Normalização; Experiência; Alteridade.

\begin{abstract}
This article discusses the process of school inclusion and its entanglements with the issue of differences and pedagogy. Part of the assumption is that inclusion is a device that affects the pedagogy of schools. The objective of this study is to reflect on the effects of the processes of school inclusion in the pedagogy of schools, and also on what subjectivities they are producing. Methodologically, this is a qualitative research that develops the documentary analysis and the description and analysis of practices according to Foucauldian references, especially using the concepts-device tool,
\end{abstract}


governmentality, subjectivity, and also the notion of experience. As results, this research indicates that the inclusion device affects the pedagogies of the schools developing inclusive processes that lead to the normalization of the subjects, generating inclusive subjectivities. But they also put into practice practices that respect and welcome subjects and their disabilities, under an ethic of otherness that is creating other subjectivities. The conclusions indicate that the statements about the differences, which make up the process of school inclusion, are mobilizing encounters with each other and building on these experiences, which transform the subjects and end up producing subjectivities sensitive to differences.

Keywords: Differences; Normalization; Experience; Otherness.

\section{INTRODUÇÃO}

A discussão central deste artigo se dá sobre a inclusão escolar e suas práticas em relação à produção de subjetividades. Discute a inclusão como um dispositivo que produz subjetividades inclusivas e subjetividades sensíveis às diferenças. Essa produção possui um enredamento com a questão das diferenças que altera os processos de normalização dos sujeitos com deficiências, colocando as diferenças em discussão e sob uma perspectiva que se encaminha para o acolhimento do Outro.

Essa escrita decorre de uma pesquisa realizada em uma escola pública de educação básicaı , sensibilizada e mobilizada para promover a inclusão das pessoas com deficiências. É conduzida por uma problematização que enreda três 'fios' que tramam: a inclusão escolar, a questão das diferenças e a pedagogia. A problemática desse estudo se dá em torno dos efeitos que enunciados sobre as diferenças, emergentes nos processos de inclusão, provocam nas práticas da escola e, consequentemente, na produção de subjetividades. Assim, as perguntas que orientaram esse estudo foram: que efeitos os processos de inclusão escolar estão produzindo na pedagogia das escolas? Que subjetividades estão sendo produzidas nos processos de inclusão escolar? 
No contexto atual, a inclusão escolar tornou-se uma máxima inquestionável e, por isso, os sistemas de ensino tencionam as escolas a envolverem seus professores, de tal forma, que é quase impossível se opor a ela. Vive-se sob os efeitos de um poder/saber que, pelo convencimento, captura as pessoas, envolvendo-as em discursos morais e éticos, para que lutem, insistentemente, por práticas que incluam as crianças e adolescentes com deficiências nas escolas comuns. Porém, esses discursos se dão imbricados com uma perspectiva política que toma a não exclusão (FOUCAULT, 2008b) como uma estratégia do neoliberalismo contemporâneo, que identifica cada indivíduo como um potencial produtivo, consumidor, e necessário as malhas do capital. Nesse sentido, a inclusão pode ser compreendida como um dispositivo que faz parte das estratégias do Estado neoliberal contemporâneo para o governamento da população, a fim de evitar riscos e, ao mesmo tempo, investir nos indivíduos para que se integrem às redes do jogo econômico promovido pelo neoliberalismo e, desta forma, passem a contribuir para a sua sustentação.

Nessa configuração dos processos de inclusão, está presente a questão das diferenças que emerge em forma de enunciados 2 , os quais compõem uma complexidade discursiva que precisa ser melhor observada. Diz-se muito e constantemente sobre o 'respeito às diferenças', mas o que compreendemos por diferença? Como a questão das diferenças aparece nos processos de inclusão? Duas questões não menos importantes, e que estão presentes neles é a associação sinonímica entre deficiência e diferença, como se o sujeito com deficiência fosse $\boldsymbol{o}$ diferente e os demais, iguais; e a outra questão, é a atitude de 'tolerância', de 'respeito às diferenças', que se transforma em soberba do eu diante do outro.

Os enunciados que formam o discurso de tolerância estão permeados pela arrogância e, por isso, retiram o direito da diferença existir, como se a sua existência dependesse da concessão de alguém: 'eu tolero a sua existência'. Sob este viés, o enunciado do 'respeito às diferenças' contribui com a lógica neoliberal, que objetiva incluir todos nas forças produtivas do mercado, porque as diferenças podem ser um potencial criativo para colocar em funcionamento a competitividade que tanto interessa 
ao neoliberalismo contemporâneo. Nessa lógica, respeitar as diferenças é incluir para fazer alguma coisa com o indivíduo, tornando-o útil ao mercado.

Portanto, a crítica que esse estudo faz à inclusão como um dispositivo da governamentalidade neoliberal, é necessária não só para problematizar estes enunciados do 'respeito às diferenças', interessados em normalizar o sujeito pelos processos inclusivos, como também para possibilitar pensar a inclusão escolar para além disso.

Os efeitos desses enunciados sobre as diferenças, presentes nos processos de inclusão são perceptíveis na pedagogia (ou nas pedagogias³) da escola, campo empírico dessa pesquisa. Por isso, a pedagogia, aqui entendida como o conjunto de saberes e práticas planejadas e desenvolvidas pela escola em geral, torna-se um pano de fundo, no qual práticas estão sendo operadas, subjetivando a todos (professores e alunos) na escola. Nesse tecido, a inclusão, as diferenças e a pedagogia produzem diferentes subjetividades. Portanto, pode-se dizer que a escola é um local e a pedagogia um instrumento para a produção de sujeitos.

Feita essa pequena digressão de como esse estudo foi compreendendo os enredamentos entre a inclusão, as diferenças e a pedagogia, esclareço que, incomodada com essas tramas, estava suspeitando que a questão das diferenças poderia trazer para o interior da escola um anúncio sobre o Outro, sobre a alteridade. Isso potencializou essa pesquisa, pois tornou-se uma alavanca para problematizar as pedagogias da escola; para pensar como elas têm se ocupado com as diferenças e com o outro, e os efeitos dessa relação na produção de subjetividades.

A inclusão como um dispositivo biopolítico da governamentalidade neoliberal quer capturar a todos para seus jogos de mercado, por isso acaba produzindo subjetividades inclusivas . No entanto, a inclusão escolar também pode desencadear pedagogias que promovam uma relação com o Outro sugerindo uma experiência que produz subjetividades sensíveis às

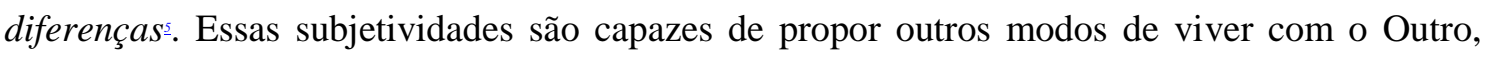
afastando-se dos processos de normalização e de condução do outro à mesmidade, que frequentemente encontramos nos processos de inclusão escolar.

Sob essas perspectivas, esse estudo reflete sobre uma realidade escolar, descrevendo e analisando o processo de inclusão que é operacionalizado pelas 
pedagogias da escola e, principalmente, refletindo sobre as subjetividades que estas estão produzindo: subjetividades inclusivas e subjetividades sensíveis às diferenças.

É preciso esclarecer ao leitor que a inclusão escolar é abordada nessa escrita como um dispositivo, corroborando o sentido trabalhado tanto por Foucault, quanto por Agamben e Deleuze. Esses filósofos o discutem sob nuances diferentes, porém possíveis de se estabelecer conexões entre elas. Destaco a compreensão de Foucault que o define como uma rede de poder e saber que "[...] engloba discursos, instituições, organizações arquitetônicas, decisões regulamentares, leis, medidas administrativas, enunciados científicos, proposições filosóficas, morais, filantrópicas" (FOUCAULT, 2006a, p. 244), que regulam formas de vida e conduzem indivíduos e populações, subjetivando-os.

A noção de dispositivo é apresentada no pensamento de Agamben como "qualquer coisa que tenha a capacidade de capturar, orientar, determinar, interceptar, controlar os gestos, as condutas, as opiniões e os discursos [...]" (AGAMBEN, 2009, p. 40), que governa os indivíduos.

A compreensão de Deleuze (1990) sobre o dispositivo como um conjunto multilinear, ou seja, como um conjunto composto por linhas de diferentes natureza, que não se delimitam em sistemas homogêneos, mas "seguem direções diferentes, formam processos sempre em desequilíbrio[...]" (p. 01), é fulcral para esse estudo discutir a inclusão como um dispositivo que produz diferentes subjetividades.

Seguindo essa última noção apresentada por Deleuze é que essa escrita pretende mostrar como o dispositivo da inclusão escolar pode produzir subjetividades inclusivas e também subjetividades sensíveis às diferenças.

\section{DAS ESCOLHAS E DOS CAMINHOS METODOLÓGICOS}

As perspectivas e ferramentas teórico-metodológicas que teceram este estudo vinculam-se às pesquisas qualitativas, sustentadas especialmente (mas não só) pelas 
teorizações foucaultianas, utilizando-se de três ferramentas teórico-metodológicas governamentalidade, dispositivo e subjetividade - para descrever e analisar práticas pedagógicas relacionadas aos processos de inclusão escolar. A governamentalidade (FOUCAULT, 2006a) é um conceito que ajuda a identificar as relações entre o governamento de Estado sobre os indivíduos e a população, e o governamento do sujeito sobre si mesmo na produção de subjetividades. O dispositivo (FOUCAULT, 2003; DELEUZE, 1990; AGAMBEN, 2009) é aqui entendido como um conjunto de redes de poder e de saber que possuem uma positividade permitindo que heterogeneidades discursivas produzam diferentes linhas de subjetivação. A subjetividade (FOUCAULT, 1995; 1997; 2008a) envolve os processos de subjetivação que as experiências provocam nos sujeitos. Além destes, também os conceitos enunciado e experiência, sob o referencial foucaultiano (FOUCAULT, 2013), e pelas reflexões de Larrosa $(2011 ; 2017)$, possibilitaram as análises realizadas.

Foram duas estratégias metodológicas utilizadas nessa pesquisa: a descrição e análise das práticas da escola e a análise documental. O levantamento das práticas foi obtido por meio de registros da escola e também, pela observação participante que permitiu vivenciar e acompanhar práticas em desenvolvimento na escola, as quais foram registradas em um diário de campo

O conceito de práticas utilizado refere-se às práticas discursivas e não discursivas que Foucault aborda ao trabalhar com a heterogeneidade discursiva em A Arqueologia do Saber (2013) e A Ordem do Discurso (2012), para explicá-las como uma racionalidade em funcionamento constituídas e constituintes de saberes e poderes. As práticas não discursivas foram compreendidas como as estratégias pedagógicas (aulas, seminários, pesquisas, reuniões, atividades, planejamentos, organização arquitetônica, rituais, etc.) que constituem as pedagogias da escola. Já, as práticas discursivas, como sugere Fischer (2012), não podem ser confundidas com a mera expressão de falas ou ditos que um indivíduo profere, porque elas são "um conjunto de regras anônimas, históricas, determinadas num tempo e num espaço" (FOUCAULT, 2013, p. 144). Por isso, tudo o que as pessoas falam deve ser compreendido sob as amarras das dinâmicas 
de poder e saber deste tempo e, por isso, não são falas específicas de um sujeito (FISCHER, 2012, p. 79).

Os documentos, por sua vez, foram tomados não como matéria inerte que reconstitui a história, mas como Foucault (2013) nos propõe, que eles sejam vistos como monumentos, ou seja, eles possuem uma história, um significado, um contexto que os fazem existir, por isso, definem no próprio tecido documental, um conjunto de relações que dizem sobre um acontecimento. Assim, selecionei os documentos, entre oficiais (legais) e orientadores (político-pedagógicos) do processo de inclusão, emitidos pelo sistema de ensino, e também aqueles elaborados pela própria escola. Também considerei como documentos todos os registros das práticas pedagógicas da escola, inclusive, produções feitas pelos próprios alunos e professores, que encontrei nos arquivos da coordenação pedagógica. Desta forma, a materialidade foi composta pelas práticas (da escola, dos professores e dos alunos) e pelos documentos (orientadores do sistema de ensino, e da própria escola).

A seguir, discuto a noção de dispositivo que é incorporada à inclusão escolar e na sequência, apresento a discussão dos resultados dessa pesquisa.

\section{A INCLUSÃO ESCOLAR COMO UM DISPOSITIVO}

A inclusão pode ser compreendida como um "poderoso e efetivo dispositivo biopolítico $^{z}$ a serviço da segurança das populações" (VEIGA-NETO, LOPES, 2007, p. 949). Poderoso, porque captura a todos de tal forma que não haja possibilidades de oposição à inclusão; efetivo, porque a cada dia mais e mais saberes são produzidos pelas estratégias de inclusão, protagonizadas nos espaços escolares, e que se expandem para o conjunto das famílias e da sociedade; e, por último, está a serviço da segurança das populações, porque é um poder que está interessado em "intervir para fazer viver [...], para ampliar a vida, para controlar os acidentes, o aleatório, as deficiências, [...]" (CASTRO, 2009, p. 60). 
A noção de dispositivo que sustenta esse estudo se utiliza das teorizações de Michel Foucault (2006), George Agamben (2009) e Gilles Deleuze (1990). Foucault o apresenta como:

[...] um conjunto decididamente heterogêneo que engloba discursos, instituições, organizações arquitetônicas, decisões regulamentares, leis, medidas administrativas, enunciados científicos, proposições filosóficas, morais, filantrópicas. Em suma, o dito e não dito são os elementos do dispositivo. O dispositivo é a rede que se pode estabelecer entre estes elementos (FOUCAULT, 2006a, p. 244).

[...] entendo dispositivo como um tipo de formação que, em um determinado momento histórico, teve como função essencial responder a uma urgência, por isso é eminentemente estratégico. O dispositivo tem, portanto, uma função estratégica dominante (FOUCAULT, 2006a, p. 244).

O dispositivo está sempre inscrito num jogo de poder, estando sempre, no entanto, ligado a uma ou a configurações de saber que dele nascem, mas que igualmente o condicionam. É isto o dispositivo: estratégias de relações de força sustentando tipos de saber e sendo sustentadas por eles (FOUCAULT, 2006a, p. 246).

Para Agamben, o dispositivo é "como qualquer coisa que tenha a capacidade de capturar, orientar, determinar, interceptar, controlar os gestos, as condutas, as opiniões e os discursos dos seres viventes" (AGAMBEN, 2009, p. 40). São como "uma máquina que produz subjetivações" (AGAMBEN, 2009 p. 46).

O dispositivo funciona por meio da dinamicidade de relações heterogêneas, quais sejam: de poder, como forças que determinam as relações entre os elementos que o compõem; de saber, como a rede de discursos que se forma no seu interior; e de subjetivação, como a produção de efeitos do indivíduo sobre si mesmo. É possível observar essa descrição do dispositivo nos documentos orientadores do sistema de ensino e em práticas da escola, como segue abaixo:

a)do poder, em que estão presentes todos os direcionamentos legais a sua efetivação, além do discurso dominante e hegemônico que afirma a inclusão como um imperativo, como uma verdade:

Art. $2^{\circ}$ Os sistemas de ensino devem matricular todos os alunos, cabendo às escolas organizarem-se para o atendimento aos educandos com necessidades educacionais especiais, assegurando as condições necessárias para uma educação de qualidade para todos (BRASIL, 2010, p.1. Grifos meus). 
b) do saber, em que um conjunto de saberes difundido por profissionais experts induzem as propostas e práticas pedagógicas das escolas e dos professores:

\title{
A formação continuada na área da Educação Especial deve priorizar momentos em que a discussão seja efetivada pelos profissionais especialistas em Educação Especial em articulação com os professores que atuam nas classes comuns (RIO GRANDE DO SUL. 2014, 32. Grifos meus).
}

c) da subjetivação, em que programas de formação pedagógica conduzem o conjunto de professores a processos de sensibilização que, ao fim e ao cabo, os subjetivam para que adotem a inclusão:

\begin{abstract}
"Assisti uma palestra sobre autismo e uma das coisas que me chamou atenção foi que a palestrante comparou a inclusão como subir uma escada de 4 ou 5 degraus [...] que a gente almeja que o aluno chegue no quinto degrau [...] e aí se ele não chegou no quarto degrau, a gente pensa que não é suficiente e esquecemos que ele passou pelo primeiro, pelo segundo degrau [...] A gente não pode esquecer que o que eles aprenderam é muito, considerando que ele tem uma deficiência” (PA. Diário de campo, 2016).
\end{abstract}

Desta forma, na esteira do pensamento de Foucault, Agamben e Deleuze, a inclusão escolar é um dispositivo porque há nela uma rede composta por elementos heterogêneos:

a) um conjunto de discursos que extrapolam o campo da educação e a da pedagogia, pois provêm de diferentes lugares convergindo com princípios éticos, morais, políticos e econômicos;

b) um aparato institucional que não deixa ninguém de fora, nem criança, nem jovem, nem adulto e ainda, possui um locus específico para mantê-las confinadas sistematicamente - a escola;

c) um amparo legal, instituído por meio de uma política nacional, acompanhada por leis e decretos, e seguida por regulamentos e orientações administrativas e pedagógicas que imprimem uma obrigatoriedade; 
d) um conjunto de enunciados científicos, principalmente da psicologia, da pedagogia e da medicina que produzem verdades que organizam a ação das pessoas, a partir de saberes especializados;

e) proposições e princípios morais identificados com a filantropia orientam o campo das ações das pessoas, de maneira uníssona e sem (quase sem) contrariedade;

f) e, por fim, é possível perceber que possui uma função estratégica que intenciona resolver um 'problema', o qual está relacionado com a condução de uma população.

Deleuze (1990) vê potência no dispositivo pela heterogeneidade de forças que o atravessa, bifurcando saberes ligados a poderes que se encarregam de produzir subjetividades. Ainda, define o dispositivo como um conjunto multilinear que apresenta linhas de fugas , pois não consiste em uma estrutura fechada. Para ele, o dispositivo pode ser definido "pelo que detém em novidade e criatividade [...]", pela sua necessidade de estar constantemente se refazendo, e ainda, pela "sua capacidade de se transformar ou se fissurar em proveito de um dispositivo futuro" (DELEUZE, 1990, p. 3).

Considerando a potência do dispositivo na heterogeneidade de forças que o atravessa, foi possível identificar na materialidade dessa pesquisa enunciados sobre as diferenças que começaram a extravasar a inclusão em direção à questão das diferenças. E nesse momento foi possível dizer sobre diferentes subjetividades que estavam sendo produzidas pelas pedagogias da escola.

Como linhas de fuga, esses enunciados sobre as diferenças conduziram o presente estudo a observar tipos de subjetividades diferentes em formação nos processos de inclusão. Assim, as análises sobre as práticas dos professores apontaram a produção de subjetividades inclusivas, aquelas adequadas ao modo de vida da sociedade contemporânea que quer incluir a todos para inseri-los nos jogos produtivos do neoliberalismo, mas também subjetividades sensíveis às diferenças. Estas não estão tão interessadas em normalizar e conduzir o Outro à mesmidade, mas em reconhecer o Outro como tal, simplesmente como diferença. Na sequência, apresento essas duas possibilidades se movimentando nas práticas da escola. 


\section{A INCLUSÃO ESCOLAR PRODUZINDO SUBJETIVIDADES} INCLUSIVAS

Como Menezes (2011) apresenta em seus estudos, o Estado neoliberal tem interesse em investir na produção de subjetividades inclusivas, tanto por meio de processos de normalização dos sujeitos com deficiências, quanto por visualizar a inclusão como diretriz de conduta dos indivíduos para a vida em sociedade, mobilizando a todos para que se envolvam a fim de que ela aconteça. A expressão subjetividades inclusivas é utilizada pela pesquisadora para explicar um tipo de sujeito produzido na contemporaneidade pela ação do Estado que tem o mercado como centro de suas ações. Seus estudos nos mostram que a governamentalidade neoliberal que atua na contemporaneidade age sobre a escola e suas práticas transformando-a em "uma maquinaria de normalização para a produção de tipos específicos de sujeitos" (MENEZES, 2011, p. 171) que, ao fim e ao cabo, produzem um modo de vida que fortalece uma racionalidade neoliberal. No entendimento dessa pesquisadora, as subjetividades inclusivas são:

[...] aquelas que se ocupam de si e dos outros para que tenham condições de investimento em si na busca do desenvolvimento de habilidades, competências e aprendizagens, a partir da racionalidade neoliberal, procurando incluir-se nas redes de consumo dessa sociedade e nelas permanecer. São subjetividades que não poderão cessar nunca de se autoinvestir, afinal, a iminência da exclusão os acompanhará permanentemente; por isso, o que se busca é a condição de conquista de um estado inclusivo, e não de uma condição de inclusão [...] (MENEZES, 2011, p. 33).

É pela inclusão, como um imperativo estratégico de Estado, que a escola e suas pedagogias produzem sujeitos capazes de incluir, não só as pessoas com deficiências, mas qualquer um. Incluir tornou-se uma máxima inquestionável na contemporaneidade, não só legal, mas também como um imperativo moral (MENEZES, 2011, p. 31) que sensibiliza para que a inclusão seja uma tarefa que pertença a todos e a cada um. Assim, investimos na necessidade de estarmos dispostos à inclusão.

Nesse sentido, constatei processos de sensibilização à inclusão na escola ao percorrer os desdobramentos do seu planejamento pedagógico. Encontrei nos registros 
que a coordenação pedagógica mantinha em seus arquivos produções escritas dos alunos, decorrentes das atividades feitas em sala de aula relacionadas à inclusão das pessoas com deficiências na escola. São excertos que apontam para efeitos de sensibilização decorrentes das pedagogias da escola:

Nós vemos a inclusão como uma necessidade para o bom convívio entre as pessoas 'especiais' e as ditas 'normais' [...]. Fazendo a inclusão, as crianças ditas normais aprenderão juntas a aceitar as diferenças (aluna do Curso Normal). (Atividade didático-pedagógica. 2011).

A pedagogia da escola estava desenvolvendo práticas de sensibilização com os alunos e provocando processos de subjetivação. Isso também estava presente nas atividades de pesquisa (Projetos de pesquisa) dos alunos, relacionadas à inclusão:

Com esse trabalho temos o objetivo, não só de expandir nossos conhecimentos como também transmitir aos colegas e professores do que se trata essa deficiência, em caso de uma futura convivência com este (indivíduo autista) (Projeto de pesquisa, 2013).

Da mesma forma, nos relatórios de estágio do Curso Normal, as alunas também mostravam traços de sensibilização incorporados na docência:

\footnotetext{
A inclusão é muito mais do que receber o aluno na escola regular e integrá-lo em sala de aula com os colegas. É acompanhar o seu desenvolvimento e certificar-se de que a escola está contribuindo para o seu crescimento, não apenas na aprendizagem, mas também, preparando-o para a vida. Com o passar do tempo fui aprendendo, fui ficando experiente e o que me manteve segura foi o apoio dos professores e monitora. (Relatório de estágio, 2013).
}

A sensibilização, frequentemente, está relacionada com processos de normalização, compreendidos como formas de condução do Outro ao Mesmo. Nesses processos, a mesmidade é o ponto de partida e de chegada. Para ela, "o outro é apenas um outro que transita sem língua, sem gestos, sem rosto, e sem corpo" (Skliar, 2003, p. 66) a ser transformado no Mesmo. Nessa relação, a normalidade massacra, encarcera e domestica o Outro, empoderando a mesmidade para tornar o Outro inerte.

Nessa perspectiva, a permanência da alteridade deficiente na escola, só tem sentido quando aproximada da normalidade, mediante mudanças nos currículos e nas condutas dos sujeitos envolvidos (professores, alunos e famílias) que permitam integrála aos processos de ensino destinados aos demais ('os normais'). Por isso, Skliar nos 
alerta que "a educação especial, é antes de mais nada, a fabricação de um conjunto de dispositivos, tecnologias e técnicas que se orientam para uma normalização inventada, de um outro, também inventado - como outro deficiente" (2003, p. 156).

Ainda, Lopes (2009) esclarece que processos de normalização agem sobre o sujeito com deficiência como uma estratégia do neoliberalismo, propondo, não igualá-lo ou simplesmente, homogeneizá-lo, mas colocá-lo em circulação para estar integrado e apto a se conectar com o mercado. A condução do Outro ao Mesmo, nessa visão, seria a condução do sujeito 'anormal' (o outro) a ser um sujeito produtivo como o 'normal' (o mesmo). A educação seria o caminho e a inclusão ampliaria as condições para o sujeito ser incluído, vivendo outras formas de vida, não igual aos ditos 'normais', mas aquela que lhe é possível, porém teria a oportunidade de permanecer integrado ao jogos do mercado, mantendo-se produtivo e competitivo.

Meu objetivo nessa seção foi mostrar como o dispositivo da inclusão produz uma pedagogia que sensibiliza para a normalização e a condução do Outro ao Mesmo. Busquei nas práticas da escola evidenciar uma governamentalidade em funcionamento produzindo subjetividades inclusivas, pela ação de uma pedagogia que se propõe a trazer os sujeitos a uma certa normalidade, coadunando com os interesses do neoliberalismo contemporâneo.

Porém, ao mesmo tempo em que olhava para o processo de inclusão e fazia essas análises, também identifiquei um 'anúncio' sobre as diferenças, que passei a considerar como enunciados integrando um discurso (o discurso da inclusão). Esses enunciados sobre as diferenças se davam como um atravessamento na inclusão escolar. Assim, nesse momento, entendi que seria necessário refinar um pouco o olhar sobre o processo de inclusão para observar como esses enunciados poderiam ser produtivos nesse cenário.

\section{FISSURAS NO DISPOSITIVO DA INCLUSÃO ESCOLAR}


A partir do momento em que passei a compreender a inclusão como um dispositivo multilinear (DELEUZE, 1990), e tratar os enunciados sobre as diferenças como linhas de fuga, foi possível pensar que além de subjetividades inclusivas, também eram possíveis, subjetividades sensíveis às diferenças. Isso porque as "produções de subjetividades escapam dos poderes e dos saberes de um dispositivo para colocar-se sob os poderes e saberes de outro, em outras formas, ainda por nascer" (DELEUZE, 1990, p. 2).

Segundo Deleuze, todo dispositivo "detém novidade e criatividade" (1990, p. 3). Assim, percebi no dispositivo da inclusão, possibilidades para a existência de fissuras que poderiam fazer 'escapar' a deficiência em direção às diferenças, ou seja, enfraquecer a normalização para pensar o outro não como um outro eu, mas um outro que pode ser o que é, ou está sendo, com a existência que lhe é própria e peculiar. Isso seria possível, porque o dispositivo da inclusão, como todo dispositivo, contém uma "capacidade de se transformar ou se fissurar" (DELEUZE, 1990, p. 3).

Mas como essas fissuras se produziriam? Pelas análises realizadas sobre as práticas da escola, observei que seriam possíveis no encontro com o outro. Já mencionei anteriormente que os processos de inclusão escolar podem produzir encontros marcados pela supremacia do Eu sobre o Outro, que tendem a normalizar o sujeito para trazê-lo (ou aproximá-lo) à normalidade e à mesmidade. Este tipo de encontro se orienta pelo apagamento do outro, pela inferiorização das diferenças, pois este deve deixar de ser o que está sendo para tornar-se o que a normalidade elege como o correto.

Entretanto, os processos de inclusão também podem produzir encontros em que o respeito às diferenças se dá a partir de uma ética da alteridade, que não deseja anular ou inferiorizar as diferenças, mas reconhecê-las e acolhê-las como possibilidade de outra vida, nem superior ou inferior, simplesmente, outra forma de existência. Estes só podem ocorrer se colocada em operação outra pedagogia, que produza um encontro com o Outro marcado pelo acolhimento e pela necessidade de responder ao Outro, de modo a produzir uma ética da alteridade. 
Como nos diz Gallo (2014), a educação é sempre um encontro de singularidades, para ela existir é necessário que haja pelo menos duas singularidades em contato. No entanto, coisas diferentes podem acontecer em um encontro, podendo ser marcado pela alegria ou pela tristeza, pela dominação ou pelo respeito e acolhimento.

Portanto, as fissuras que foram observadas no encontro com o outro proporcionado pelos processos de inclusão nessa escola, estavam mostrando que ali surgia um limiar ético da alteridade, porque os professores estavam vivendo uma experiência (LARROSA, 2011) diferente, que indicava a existência de um pensamento que estava desconstruindo a relação de dominação do Eu sobre o Outro.

A experiência, segundo Larrosa (2011, p. 5), não diz sobre um simples acontecimento, como um experimento, mas sobre aquilo "que me passa, [...] que não depende de mim, $[\ldots]$ nem das minhas ideias, [...] nem das minhas intenções [...]:

\begin{abstract}
Mas, supõe [...] algo que me passa. Não que passa ante mim, ou frente a mim, mas a mim, quer dizer, em mim. A experiência supõe um acontecimento exterior a mim. Mas, o lugar da experiência sou eu. É em mim (ou em minhas palavras, ou em minhas ideias, ou em minhas representações, ou em meus sentimentos, ou em meus projetos, ou em minhas intenções, ou em meu saber, ou em meu poder, ou em minha vontade) onde se dá a experiência, onde a experiência tem lugar (2011, p. 5-6).
\end{abstract}

Segundo Larrosa (2015), a experiência é cada vez mais rara, porque o mundo em que vivemos hoje está fortemente definido pelo excesso de informação que a substitui. As experiências são substituídas por informações que levam a emissão de opiniões. Os indivíduos não têm tempo para viver experiências, pois a velocidade das informações impede a experiência.

Nesse sentido, pode-se dizer que a imperatividade da inclusão escolar e necessidade de respostas imediatas para trabalhar com os alunos que possuem deficiências não está permitindo experiências. Os professores buscam individualmente e recebem informações propagadas em cursos de formação, e a partir destas emitem opiniões de 'como trabalhar' com o aluno com deficiências. No entanto, para incluir esse aluno, faz-se necessário o tempo da experiência, o tempo do professor viver com 
cada aluno a experiência de ensinar a quem possui condições adversas àquelas dos demais.

A representação atribuída ao aluno da educação especial é a do deficiente, dotado de incapacidades e limitações, que o situa como um sujeito 'anormal' e inferior, que necessita exclusivamente de nós (os 'normais'). Porém, a experiência é capaz de descontruir os modos de representação que temos sobre esse outro.

Somente subjetividades abertas ao outro podem deixar-se afetar pelo outro, porque estas estariam destituídas do supremacia do $\mathrm{Eu}$, vulneráveis diante do outro, produzindo acolhimento e responsabilidade do Eu pelo Outro. Seriam produzidas por uma pedagogia que se ocupa do encontro com o outro sob a perspectiva da ética da alteridade proposta por Lévinas (2015).

De acordo com esse filósofo, é possível pensar uma subjetividade que não esteja tão interessada na assimilação do outro, mas que responda a ele por meio de uma sensibilidade que conduz ao acolhimento e à responsabilidade, instaurando o que ele chama de 'um para o outro' (LÉVINAS, 2015, p. 80).

Apresento a seguir, alguns recortes dos depoimentos de professoras sobre suas práticas pedagógicas desenvolvidas em sala de aula, impulsionadas pelos enunciados sobre as diferenças e que indicam o limiar de uma ética da alteridade. Nestes, elas relatam sobre o que viveram, pensaram, sentiram; sobre o que modificaram em si, nos seus modos de pensar sobre o outro, ou seja, procuram falar da sua experiência no encontro com o outro. São práticas que levam a pensar que no encontro com o outro é possível uma experiência de si que produz subjetividades sensíveis às diferenças, ou seja, subjetividades afetadas pelo outro:

\footnotetext{
"Em sala de aula tive várias situações sobre as diferenças que me marcaram. Eu tinha um aluno que não parava na sala de aula, corria, caminhava o tempo todo, se isolava dos demais, não participava das atividades [...]. Inicialmente ele não ouvia, ou não queria ouvir, ficava sempre longe. Após algum tempo fui colocando ele ao lado da caixa de livros e eu dava algumas figuras para ele olhar, alguns livros para manusear, até que ele começou a se aproximar, ficar mais perto de mim. Os demais alunos o rejeitavam, reclamavam e para mim isso era difícil contornar. Ainda assim, cada dia ia pedindo para que um colega sentasse ao seu lado para dividir material, ajudar [...]. Essas coisas
} 
provocaram em mim uma nova forma de ver o outro e de pensar o mundo. Isso provocou uma revolução [...] mudei atitudes, comprometimento e mais responsabilidade social. O importante hoje é encarar as diferenças [...] aprendi muito”. (PB. Diário de campo. 2016).

Outra professora comentou sobre sua experiência com uma aluna cega nas aulas de Artes:

\begin{abstract}
"Não é fácil [...] a gente se sente perdida [...] às vezes eu pensava: 'Nossa! Como fazer isso agora?' [...]. Eu não sabia trabalhar com ela, mas fui propondo coisas e ela ia trabalhando e eu via que ela gostava. [...]. Sempre tentava descrever oralmente, mas ao mesmo tempo eu pensava, 'mas o que ela está pensando?' Isso mexe com a gente, instiga, dá medo [...]. Como é algo que não é novo, mas é novo ao mesmo tempo, é bem difícil. Claro que mudou muito em mim, a minha visão [...]. A gente espera que todos comecem no primeiro degrau e cheguem todos ao último, mas dependendo de cada aluno, chegarão em degraus diferentes. Não aprendemos de modo igual, cada objetivo, cada aprendizagem é única e marca cada um de um jeito. Por isso, não espero que todos aprendam tudo ao mesmo tempo. Quando pensei isso, me acalmei, porque eles não precisam seguir juntos, podem seguir no seu tempo. Assim, podemos perceber que todos são diferentes, que cada ser humano tem um potencial diferente, a gente não pode comparar, isso é individual. Todos percorrem o caminho, mas com diferenças. Não espero que eles façam as coisas como eu penso. Eles vão criar a sua própria forma de trabalhar. Eu passei a pensar de forma diferente, desde que tive meu primeiro aluno com deficiência, sempre trabalhei pensando que cada um pode ser diferente, não precisamos seguir modelos, não somos máquinas produtivas. (PC. Diário de campo. 2016)
\end{abstract}

Nesses relatos, o encontro com o outro não é um simples encontro, mas uma abertura ao outro. Há uma relação entre sujeitos que se dá por fissuras no dispositivo da inclusão, em que seus mecanismos de poder e saber levam as professoras a pensarem sobre si, a se analisarem e se narrarem, como em um processo de subjetivação produzido pela experiência de si (FOUCAULT, 2006b; SILVA, 1994).

No primeiro excerto, a professora fala de um encontro que se deu aos poucos, a partir dos seus investimentos aproximativos com um aluno, na tentativa de trazê-lo ao encontro. Denota-se nesse relato o tempo de espera da professora pelo estabelecimento de uma relação de ensino e de aprendizagem deste aluno, corroborando com Larrosa (2017) quando diz que se estamos acelerados nada acontece, pois a velocidade e a pressa são inimigas mortais da experiência A experiência vai acontecendo e, como a professora (PB) afirma, provoca uma 'revolução' no seu pensamento, mudando atitudes 
e comportamentos para manter um encontro com o outro. A experiência é isso, é transformação do sujeito. De acordo com Larrosa (2017):

O sujeito da experiência se define não por sua atividade, mas por sua passividade, por sua receptividade, por sua disponibilidade, por sua abertura. [...] de uma passividade feita de paixão, de padecimento, de paciência, de atenção, como uma receptividade primeira, como uma disponibilidade fundamental, como uma abertura essencial (2017, p. 25-26).

Assim, embora capturada pela imperatividade da inclusão, esta professora está aberta ao outro para inventar outros modos de viver com ele, a fim de que este possa ocupar um lugar que seja seu.

No segundo relato, a professora (PC) traz sua experiência desde o seu estranhamento com o outro deficiente, passando por um exercício de respeito e de acolhimento, que a leva a dizer que não espera que seus alunos "façam as coisas como eu penso". Ela não espera que seus alunos sigam modelos, pois acredita que "todas as possibilidades são válidas". O que essa professora diz indica uma experiência no encontro com o outro, que aponta um limiar ético da alteridade. Por meio da inclusão, ela admite "perceber que todos são diferentes" e que eles podem ser assim como são, e não precisam ser 'corrigidos' e conduzidos ao mesmo. Nesse relato também é possível perceber que o Outro é quem age sobre o Eu, indicando a destituição da primazia do Eu sobre o Outro, como Lévinas (2015) propõe ao referir-se à sensibilidade como vulnerabilidade do $\mathrm{Eu}$, que, no acolhimento do Outro, torna-se responsável por ele. Como diz Miranda (2008), a proximidade conduz a subjetividade a responder como responsabilidade pelo Outro:

\footnotetext{
Uma responsabilidade que, por sua vez, não deriva da liberdade do sujeito soberano (o sujeito não tem a liberdade de escolher a sua responsabilidade); e sim, constitui a sua própria subjetividade e, como tal, não se subordina à liberdade. Responsabilidade que tem sua origem na relação de proximidade com o Outro, e que é tecida na sensibilidade como vulnerabilidade da subjetividade (MIRANDA, 2008, p. 71).
}

A subjetividade exposta ao Outro não escapa a uma resposta. $\mathrm{O}$ Eu, inevitavelmente, terá que responder, seja por palavras ou gestos de omissão, seja por uma resposta de acolhimento. 
Esses depoimentos apresentam-se como visibilidades que 'cintilam' experiências decorrentes dos enunciados sobre as diferenças que conduzem os professores a investir em outras formas de viver com o outro. São respostas que são dadas no encontro com o outro, as quais fissuram o dispositivo da inclusão escolar que normaliza, para fluir linhas de fuga em direção ao acolhimento das diferenças.

Nesse encontro com o outro surge uma ética da alteridade que reconstrói as subjetividades "não mais a partir do Eu, mas pela estrutura um-para-o-outro, na qual a subjetividade é descrita nos termos de acolhimento e responsabilidade (MIRANDA, 2014, p. 468).

Essas subjetividades são sensíveis às diferenças, estão abertas às diferenças, não para simplesmente respeitá-las ou tolerá-las, mas para reconhecer que seu mundo não é único, que existem outros mundos, e o outro é a possibilidade de múltiplos mundos. Assim, as diferenças poderiam existir sem a ameaça de serem classificadas e inferiorizadas, sem serem tomadas como o desvio da norma, como um erro a ser corrigido, mas como outras formas de vida.

\section{CONSIDERAÇÕES FINAIS}

Com esse artigo procurei construir uma reflexão acerca dos processos de inclusão escolar, porém não assumindo uma posição contrária ou favorável, mas interessada em problematizar o que pensamos e o que fazemos com ela. Vivemos um imperativo da lei quanto à inclusão das pessoas com deficiências nas escolas comuns, mas a cultura escolar e a formação dos professores, em geral, nunca levou em consideração as diferenças na escola. Assim, a escola se constituiu como um espaço normalizador de condutas, talvez nisso concentre as dificuldades em transformar-se em um espaço inclusivo para todos.

Apesar disso, a entrada das pessoas com deficiências na escola comum têm provocado repensar suas pedagogias. Nesse sentido, esse estudo pode contribuir para 
que elas não assumam uma postura ingênua diante da inclusão, porque ao mesmo tempo em que esta esteja sustentada por princípios morais e éticos, também está capturada pela lógica neoliberal contemporânea, que não quer ninguém fora dos jogos econômicos. $\mathrm{Na}$ configuração atual, a inclusão é condição para que os indivíduos possam participar dos jogos de mercado, desenvolvendo-se competitivamente, pois, tanto os ditos 'normais' quanto os ditos 'anormais' interessam ao capitalismo. Assim, a inclusão passa a ser uma necessidade e não uma possibilidade! Por isso, com frequência, a inclusão se constitui em processos de normalização e de condução do Outro ao Mesmo, produzindo subjetividades inclusivas.

Os estudos de Foucault, Agamben e Deleuze foram importantes para compreender a inclusão escolar como um dispositivo que coloca em funcionamento uma biopolítica que governa a todos (com deficiência ou sem deficiência) em torno de uma lógica (racionalidade) neoliberal contemporânea. Mas também, para perceber que há uma governamentalidade ética que se instaura no encontro das relações de governo de uns sobre os outros e do governo do próprio sujeito, que pode produzir outras formas de condução do outro e de si próprio. Estas podem ser possibilidades de resistência à governamentalidade neoliberal, e de invenção de outras formas de condução da vida. Essas formas são possíveis porque o dispositivo da inclusão não possui uma estrutura fechada, e no contexto dessa pesquisa seus processos encontravam-se atravessados por enunciados que diziam sobre as diferenças.

Considerando essa governamentalidade ética, investi em análises sobre as experiências que padecem os sujeitos no encontro com o outro, provocado pelas pedagogias inclusivas da escola. Ancorando-me no pensamento de outros filósofos como Lévinas e Larrosa, foi possível compreender a inclusão escolar como um dispositivo que produz diferentes subjetividades. Assim, além das subjetividades inclusivas, que estão sendo moduladas para incluir em uma perspectiva que atenta para a produtividade do sujeito com deficiências, também a produção de subjetividades sensíveis às diferenças são possíveis. 
A materialidade dessa pesquisa possibilitou refletir sobre o encontro com o outro como uma possibilidade para o Eu enfraquecer sua primazia sobre o Outro, abrindo-se para a alteridade e reconhecendo-a como uma outra possibilidade de existência. Esse enfraquecimento da subjetividade se dá por uma sensibilidade que é marcada pela vulnerabilidade. O Eu, vulnerável, se abre para o Outro e produz acolhimento e responsabilidade, seguindo uma ética que vem da exterioridade, do Outro.

\section{REFERÊNCIAS:}

AGAMBEN, G. O que é o contemporâneo? E outros ensaios. Chapecó, SC: Argos, 2009.

BRASIL. Conselho Nacional de Educação. Resolução CNE n n $^{\mathbf{0}}$, de 14 de dezembro de 2010. Fixa Diretrizes Curriculares Nacionais para o Ensino Fundamental de 9 (nove) anos. Disponível em: 〈http://portal.mec.gov.br/dmdocuments/rceb007_10.pdf > Acesso em: 10 abr. 2016.

DELEUZE. G. ¿Que és un dispositivo? Michel Foucault, filósofo, Barcelona: Gedisa, p. 155-161, 1990. Tradução de Wanderson Flor Nascimento. Disponível em: <http://escolanomade.org/2016/02/24/deleuze-o-que-e-um-dispositivo/> Acesso em: 10 mar. 2015.

CASTRO, E. Vocabulário de Foucault: um percurso pelos seus temas, conceitos e autores. Belo Horizonte: Autêntica, 2009.

FISCHER, R. B. Sobre discursos e análise a enunciativa. In: . Trabalhar com Foucault: arqueologia de um paixão. Belo Horizonte: Autêntica, 2012.

FOUCAULT, M. O poder e o sujeito. In: DREYFUS, H.; RABINOW, P..Michel Foucault: uma trajetória filosófica para além do estruturalismo e da hermenêutica. Rio de Janeiro: Forense Universitária, 1995.

Subjetividade e verdade. In:

France (1970-1982). Rio de Janeiro: Zahar, 1997. Resumo dos Cursos do Collège de

Em Defesa da Sociedade: curso no Collège de France (1975-1976). São Paulo: Martins Fontes, 1999.

História de sexualidade I: A vontade de saber. 15. ed. Rio de Janeiro: Edições Graal, 2003. 
Microfísica do poder. 22. ed. Rio de Janeiro: Edições Graal, 2006a.

A hermenêutica do sujeito. 2 ed. São Paulo: Martins Fontes, 2006 b.

Tecnologías del yo. Buenos Aires: Paidós, 2008a.

Nascimento da Biopolítica: Curso Collège de France. São Paulo: Martins Fontes, 2008b

. A Ordem do discurso. Aula inaugural no Collège de France, pronunciada em 2 de dezembro de 1970. 22. ed. São Paulo: Edições Loyola, 2012.

A Arqueologia do saber. 8. ed. Rio de Janeiro: Forense Universitária, 2013.

GALLO, S. Eu, o outro e tantos outros: educação, alteridade e filosofia da diferença, 2014. Disponível em: https://territoriosdefilosofia.wordpress.com/2014/12/05/eu-ooutro-e-tantos-outros-educacao-alteridade-e-filosofia-da-diferenca-silvio-gallo/ Acesso em: 27 nov. 2018.

LARROSA, J. Tecnologias do eu e educação. In: SILVA, Tomaz T. (Org.). O sujeito da educação: estudos foucaultianos. 2. ed. Petrópolis, RJ: Vozes, 1994_

Experiência e alteridade em educação. Revista Reflexão e Ação, Santa Cruz do Sul, v.19, n. 2, p. 04-27, jul./dez. 2011.

Tremores: escritos sobre experiência. Belo Horizonte: Autêntica, 2017.

LÉVINAS, E. Ética e infinito. Trad. Jesús María Ayuso Díez. Madri: Ed. Antônio Machado, 2015.

LOPES, M. C. Políticas de inclusão e governamentalidade. Educação e Realidade, Porto Alegre, v. 34, n. 2, p. 153-169, maio/ago., 2009.

MENEZES, E. da C. P. de. A maquinaria escolar na produção de subjetividades para uma sociedade inclusiva. 2011. 189 p. Tese (Doutorado em Educação) Universidade do Vale do Rio dos Sinos, São Leopoldo, RS, 2011.

MIRANDA, J. V. A. Ética da alteridade e educação. 2008. 188 p. Tese (Doutorado em Educação) - Universidade Federal do Rio Grande do Sul, Porto Alegre, RS, 2008.

Lévinas e a reconstrução da subjetividade ética: aproximações com o campo da educação. Revista Brasileira de Educação, Rio de Janeiro, v. 19, n. 57, abr./jun., p. 465-475, 2014. Disponível em: <http://www.scielo.br/pdf/rbedu/v19n57/v19n57a10.pdf >. Acesso em: 12 out. 2016. 
RIO GRANDE DO SUL. Secretaria Estadual da Educação. Caderno Pedagógico 1. A educação especial na perspectiva da educação inclusiva: diretrizes orientadoras para a rede estadual do ensino do Rio Grande do Sul. 2014.

SILVA, T. T. (org.). O sujeito da educação: estudos foucaultianos. 2. ed. Petrópolis: Vozes, 1994.

SKLIAR, C. A invenção e a exclusão da alteridade 'deficiente' a partir dos significados da normalidade. Educação e Realidade. Porto Alegre, n. 24 (2), p.15-31, jul. /dez., 1999.

Pedagogia (improvável) da diferença: e se o outro não estivesse aí? Rio de Janeiro: DP\&A, 2003.

VEIGA-NETO, A.; LOPES, M. C. Inclusão e governamentalidade. Educação e Sociedade, Campinas, v. 28, n. 100 - Especial, p. 947-963, out. 2007.

ZOURABICHVILI, F. O vocabulário de Deleuze. Tradução André Telles, 2004. Disponível em: http://escolanomade.org/wp-content/downloads/deleuze-vocabulariofrancois-zourabichvili.pdf Acesso em 4 out. 2018.

1 Esta escola oferta todos os cursos da educação básica, inclusive o Curso Normal

$\underline{2}$ Segundo Foucault, um enunciado não é uma simples fala ou um escrito qualquer, mas ele é uma função de existência, ou seja, ele possibilita a emergência de falas, frases e ditos em um certo domínio de discursos.

3 A expressão 'pedagogias' aparece nesse texto sob o pretexto de incluir a compreensão de que não há 'uma pedagogia' em funcionamento na escolas, mas 'pedagogias' que podem diferir e produzir diferentes subjetividades.

4 Termo cunhado pela pesquisadora Eliana Menezes para referir-se às subjetividades adequadas ao modo de vida da sociedade contemporânea (MENEZES, 2011).

$\underline{5}$ Termo trabalhado por esta pesquisadora para dizer sobre a produção de subjetividades que se refazem na experiência do encontro com o outro, produzindo uma ética da alteridade.

6 Os registros das práticas de professores são identificados como: Professora A, B e C (PA, PB, PC).

7 O dispositivo biopolítico atua como estratégia da biopolítica para lidar com a população. A biopolítica é uma tecnologia que se utiliza de mecanismos de poder sobre a multiplicidade dos homens e de sua vida para extrair um saber sobre ela e assim definir o campo de intervenção de seu poder (FOUCAULT, 1999).

8Segundo Deleuze (ZOURABICHVILI, 2004) são fugas que fazem um sistema vazar levando ao imprevisível. São linhas que escapam rompendo paredes e margens em direção ao novo. 
